\title{
Improving the Dimensioning of Piping Networks and Network Layouts in Low-Energy District Heating Systems Connected to Low-Energy Buildings: A Case Study in Roskilde, Denmark
}

\section{Tol, Hakan; Svendsen, Svend}

\section{Published in:}

Energy

Link to article, DOI:

10.1016/j.energy.2011.12.002

Publication date:

2011

Document Version

Early version, also known as pre-print

Link back to DTU Orbit

Citation (APA):

Tol, H., \& Svendsen, S. (2011). Improving the Dimensioning of Piping Networks and Network Layouts in LowEnergy District Heating Systems Connected to Low-Energy Buildings: A Case Study in Roskilde, Denmark. Energy, 38(1), 276-290. https://doi.org/10.1016/j.energy.2011.12.002

\section{General rights}

Copyright and moral rights for the publications made accessible in the public portal are retained by the authors and/or other copyright owners and it is a condition of accessing publications that users recognise and abide by the legal requirements associated with these rights.

- Users may download and print one copy of any publication from the public portal for the purpose of private study or research.

- You may not further distribute the material or use it for any profit-making activity or commercial gain

- You may freely distribute the URL identifying the publication in the public portal 


\title{
Improving the Dimensioning of Piping Networks and Network \\ Layouts in Low-Energy District Heating Systems Connected to Low-Energy Buildings: A Case Study in Roskilde, Denmark
}

\author{
Tol H. İ. ${ }^{1, *}$, Svendsen S. ${ }^{1}$ \\ ${ }^{1}$ Technical University of Denmark, Department of Civil Engineering, Section of Building Physics and Services, \\ Brovej, Building 118 DK-2800, Kgs. Lyngby, Denmark
}

\begin{abstract}
The paper presents a method for the design of a low-energy district heating (DH) system, concerning the studies of different pipe-dimensioning methods, substation types and network layouts. Computations were carried out separately on each of the pipe segments of which the DH network consisted. A simultaneity factor was taken account in connection with each of these pipe segments. The applicability of the developed optimization method was investigated with outcomes of its being highly useful in the pipe dimensioning and of its being superior in respect to traditional dimensioning methods. It was shown that an appreciable reduction in heat loss from the DH network could be achieved. The optimal pipe dimensions found were evaluated by use of the commercial software Termis with input of several randomly generated heat demand scenarios involving peak winter conditions. The effects of the network type on the pipe dimensions were investigated for substations of different types containing buffer tanks and heat exchangers and for booster pumps installed at the DH network. Two types of network layouts were compared in terms of satisfaction of customers concerning the supply temperatures and heat loss within the DH network to prevent excessive drops in supply temperature during the summer months.
\end{abstract}

Keywords: low-energy; district heating; network layout; pipe dimensioning; simultaneity factor; optimization method.

${ }^{*}$ Corresponding author. Tel: +45 452550 25; fax: +45 45883282.

E-mail addresses: hatol@byg.dtu.dk (H. İ. Tol), ss@byg.dtu.dk (S. Svendsen). 


\section{Introduction}

Efforts to reduce energy consumption in European buildings, together with intensified energy efficiency measures that are being undertaken, and the increasing exploitation of renewable energy sources for providing heat have led to the search for a more adequate conception and better network design of new-generation District Heating (DH) systems for low-energy buildings [1-6]. Both the integration of new low-energy buildings and the low-energy renovation of existing buildings increase the percentage of heat loss from the piping network of a traditional DH system. Heat loss from the network has a significant impact on the costeffectiveness and energy efficiency of a DH system [7-9]. In one project in this area [10] it was found that a low-energy $\mathrm{DH}$ system operating at very low temperatures, $55^{\circ} \mathrm{C}$ in the case of supply and $25^{\circ} \mathrm{C}$ in the case of return, can satisfy the heating demand of consumers through adequate control of the substations [9,11-13]. There are also studies [12,14,15] which have shown that indoor heating systems in already existing buildings can continue satisfying the heat demand at low supply temperatures. In addition, certain heat loss can be avoided through operation at low temperatures $[11,16]$, providing savings in heat production as well $[9,14,17-21]$. The heat loss from a DH network is affected by the diameter of the pipes and the insulation material employed, as well as by the temperature of the supply and by the return heat carrier medium. Accordingly, special attention needs to be directed at the dimensions of the DH piping network so as to take advantage of DH in the best possible way [2,5,22-26]. Traditional methods of DH pipe dimensioning involve use of a size-searching algorithm in which the lowest pipe diameter possible is defined in accordance with the maximum velocity and/or with the maximum pressure gradient, so as to avoid the installation of an overdimensioned and unnecessarily costly DH network [4,16,23,27]. The risk of obtaining an 
over-dimensioned piping network can be prevented by optimal design of the DH network $[28,29]$.

It is not expected that each consumer will consume heat at a full demand level or at exactly the same time. This is the basic idea behind the use of simultaneity factor [30]. Special attention was thus directed at determining the heat load in each pipe segment, consideration being given to the consumer load to which each pipe segment is subjected. Three methods for the dimensioning of piping networks, two of them based on use of maximum pressure gradient criteria [31] and the other on optimization [11,28,29,32,33], were investigated, their being compared in terms of heat loss from the DH network. Also, DH networks connected to two different substations each containing a buffer tank or a heat exchanger, used for domestic hot water (DHW) production were investigated. In addition, further opportunities for reducing the dimensions involved were studied by installing additional booster pumps in the DH network together with the substations containing heat exchangers for DHW production. The reliability of the DH network with optimal pipe dimensions was evaluated by use of the hydraulic and thermal simulation software Termis, in which peak winter scenarios representing different heat consumption profiles of consumers were compared, these being based on the degree of simultaneity of the heat demands of the different consumers [34]. Supply temperature in the DH network is lowered, in particular through the heat consumption being reduced when there is no need for space heating (SH) and through consumers being absent during holidays and vacation periods. Two types of network layouts were investigated - branched networks with bypasses at leaf nodes and looped networks without bypasses with the aim of determining how best to prevent marked drops in the supply temperature and at the same time keep heat loss from the DH network at a minimum. The heat consumption profiles of consumers have been found to affect the operation of DH networks $[11,36]$. Accordingly, different DH network layouts were investigated in terms of energy performance 
under conditions of low heat demand in the summer, on the basis of time series simulations involving use of the Termis software and of different scenarios.

\section{Methods}

\subsection{Description of the Site}

A case study was carried out concerned with a suburban area of Trekroner in the municipality of Roskilde in Denmark, in which extensive building construction is planned (Figure 1), the DH system there supplying heat to 165 low-energy houses. The piping network is to have a total length of about $1.2 \mathrm{~km}$ in the layout of the branched type and $1.4 \mathrm{~km}$ in the layout of the looped type, the length of the end-user connections not being figured in here. Future network extension is assumed to not be required. It is also assumed that consumers will have a peak heat demand of $2.9 \mathrm{~kW}$ in connection with $\mathrm{SH}$, of $32.3 \mathrm{~kW}$ if a substation having a heat exchanger is employed, and of $3 \mathrm{~kW}$ with use of a substation having a 120 litre buffer tank for DHW production (more detailed information regarding this can be found in [37-39]). The heating demand data for $\mathrm{SH}$ and for DHW was found to meet the requirements defined for heating demand data by the software Be06, which was updated in 2011 through development of the new version of it, Be10 [40].

Since the heat loss from twin pipes is less than that from single pipes with the same dimensions, and since the cost of installing twin pipes is usually less for dimensions of up to DN 100 [37,41], the network was dimensioned in accordance with the catalogue of commercially available twin pipes within the range of $\{10,11.6,15,20,26\}$ for $\mathbf{T P D}_{\text {Alu }}$ and of $\{37.2,43.1,54.5,70.3,82.5\}$ for $\mathbf{T P D}_{\mathrm{St}}[42,43]$. TPD refers to the set of inner diameters of the pipes that are commercially available, the subscript "Alu” referring to AluFlex twin pipes and "St" to steel twin pipes. A general set of inner diameters including both AlueFlex twin pipes and steel twin pipes was defined as $\mathbf{T P D}=\mathbf{T P D}_{\text {Alu }} \cup \mathbf{T} \mathbf{T} \mathbf{D}_{\mathrm{st}}$. The use of higher values for the maximum allowable pressure drop for dimensioning purposes, can result in a 
sharp decrease in the pipe sizes involved, in heat loss from the DH network and in higher pipe installation costs, at the same time as the operating costs remain constant [28]. The maximum static design pressure for AluFlex twin pipes (10 bara) was considered as a constraint in setting the maximum allowable pressure drop for the dimensioning methods [44]. The overall maximum allowable pressure drop, $\Delta P_{\text {Max }}$ for the supply and for the return lines was set to 8 bar, for a holding pressure of 1.5 bara on the return line at the heat source. Also, the minimum pressure drop was set to 0.5 bar for the substation of each consumer. The ground temperature was set to $2{ }^{\circ} \mathrm{C}$ for peak winter conditions and $14{ }^{\circ} \mathrm{C}$ for the summer months [45].

\subsection{District Heating Network Model}

In the present paper, the calculations were applied mainly to branched networks. The branched network model makes use of the node list array $\mathbf{N}$ and the pipe list array $\mathbf{P}$ $[11,44,46]$, the end-user connections (also known as the branch pipe) being excluded so as to make calculations easier (Figure 1) [27]. In accordance with the DH network model, the heat source at the root node $r$ was defined as supplying heat through the routes $R$ that end at the leaf nodes $l$ (i.e. nodes without any successor node). The pipe list array $\mathbf{P}$ consists of the pipe segments $P_{i-1, i}$ that connect the node $i-1$ to the node $i$, in the order of root node $r$ to leaf node $l$, together with information concerning the number of consumers $C\left(N_{i}\right)$ connected to the node $N_{i}$ and the length of the pipe segments $L\left(P_{i-1, i}\right)$. The routes of a network $R_{l}$ are the branches starting from the root node $r$ and extending to the destination of the leaf node $l$ in question. Accordingly, functions applying to $R_{l}$ are calculated for the entire route. The path sets $P S_{l}$; from the root node $r$ to the respective leaf node $l$, and $P S_{i j} l$; from a node $i$ to the respective node $j$ through the route $l$ were defined as sequences of linked pipe segments. The functions applying both to $P S_{l}$ and to $P S_{i j \_l}$ were put to use on each of the pipe segments separately within the path set in question. 
The pipe segments of the branched type DH network were dimensioned according to the peak heat demand by including simultaneity factor as a function of the cumulative number of consumers. Each heat-demanding node in the DH network model was defined as supplying heat to six consumers, except for the nodes $i=6,11,12,24,29,30$ and 35 , which supply heat to three consumers each. The cumulative number of consumers for each node in the network was calculated using Eq. (1).

$C C\left(N_{i-1}\right)=C\left(N_{i-1}\right)+\sum_{k=l}^{k=i} C\left(N_{k}\right) \quad \forall l$ where $N_{k} \in \Gamma^{+}\left(N_{i-1}\right) \subset P S_{l}$

where $C C\left(N_{i}\right)$ is the cumulative number of consumers at the node $i$ and $\Gamma^{+}\left(N_{i}\right)$ denotes the set of all successor nodes in relation to the node $i$.

The simultaneity factor for space heating was calculated on the basis of the cumulative consumer load on each pipe segment, using Eq. (2) [47].

$S F_{S H}\left(N_{i}\right)=0.62+\frac{0.38}{C C\left(N_{i}\right)}$

where $S F_{S H}$ refers to the simultaneity factor for space heating.

The heat load for SH and for DHW was calculated for each pipe segment, using Eq. (3) and Eq. (4), respectively, and the total heat load by use of Eq. (5).

$\dot{Q}_{S H L}\left(N_{i}\right)=S F_{S H}\left(N_{i}\right) \times C C\left(N_{i}\right) \times \dot{Q}_{S H D}$

where $Q \square S H L$ refers to the heat load for SH and $Q_{\dot{S} H D}$ denotes the unique heat demand for SH of the individual consumer, both expressed in $\mathrm{kW}$.

$\dot{Q}_{D H W L}\left(N_{i}\right)=A \times C C\left(N_{i}\right)+B \times C C\left(N_{i}\right)^{0.5}+C$

where $Q \square_{D H W L}$ refers to the heat load for DHW expressed in $\mathrm{kW}$, where $A=1.19, B=1.5$ and $C=0.3$ for a substation having a $120 \mathrm{l}$ buffer tank and where $A=1.19, B=18$ and $C=13.1$ for a substation having a heat exchanger [37].

$\dot{Q}_{H L}\left(N_{i}\right)=\dot{Q}_{S H L}\left(N_{i}\right)+\dot{Q}_{D H W L}\left(N_{i}\right)$ 
where $Q \square_{H L}$ is the total heat load at node $N_{i}$ both for SH and for DHW, the integrated simultaneity factor depending upon the cumulative number of consumers.

The mass flow was calculated in accordance with the heat load by use of Eq. (6).

$\dot{m}\left(N_{i}\right)=\frac{\dot{Q}_{H L}\left(N_{i}\right)}{h_{f}\left(T_{S}\right)-h_{f}\left(T_{R}\right)}$

where $\dot{m}$ refers to mass flow in $\mathrm{kg} / \mathrm{s}$ and $h_{f}(T)$ is the specific enthalpy [kj/kg] of the heat carrier medium at temperature $T\left[{ }^{\circ} \mathrm{C}\right]$, the subscripts $S$ and $R$ indicating the temperatures of the supply and the return heat carrier medium, respectively.

The pressure drop in the different pipe segments was calculated using the Darcy-Weisbach equation because of the advantage it has of being strictly dependent upon the kinematic viscosity of water, which is a function of the temperature and is applicable under different flow conditions $[44,48]$. The friction coefficient $\mathrm{f}$ was calculated using the Clamond algorithm, which is simple, fast, accurate and robust for solving the Colebrook equation [49]. Calculation of the pressure drop was carried out for the supply and the return lines separately on the basis of their temperatures.

Heat loss from the DH network was calculated using Eq. (7), which takes account of differences in temperature and of the linear temperature-dependent thermal coefficient between the medium and the ground around it for both the supply and the return lines.

$\dot{Q}_{\text {Loss }}=\sum_{i=1}^{n_{i}}\left\{L\left(P_{i-1, i}\right) \times\left[U_{S}\left(D\left(P_{i-1, i}\right)\right) \times\left(T_{S}-T_{G}\right)+U_{R}\left(D\left(P_{i-1, i}\right)\right) \times\left(T_{R}-T_{G}\right)\right]\right\}$

where $Q \square_{\text {Loss }}$ is the total heat loss from the DH network, which has $n_{i}$ nodes, $U(D)$ being the linear thermal coefficient $[\mathrm{W} /(\mathrm{mK})]$ computed as a function of the inner diameter $D[\mathrm{~mm}]$ and of the ground temperature $T_{G}$ around the pipe segment $\left[{ }^{\circ} \mathrm{C}\right]$. The subscripts $S$ and $R$ indicate the temperature of the supply and the return heat carrier medium, respectively.

This explicit U-value-based formulation is satisfactory and practical from an engineering standpoint. In the heat loss calculations, drops in temperature within the network, the 
temperature dependency of the thermal conductivity, and the ageing of the PUR (polyurethane) foam were neglected [45,50,51].

\subsection{Dimensioning Methods}

After determining the basic input data for the DH network, such as geographical information regarding the area as well as the heat source and the heat load on the pipe segments, it is essential that one select an appropriate design method for dimensioning the pipe segments, in order to avoid over-dimensioning of them, which can result in excessively high network installation costs and a high degree of heat loss. The following dimensioning methods were employed for the branched DH networks connected to substations having $120 \mathrm{l}$ buffer tanks for DHW production.

\section{Dimensioning Method 1. The Maximum Pressure Gradient, Critical Route Method}

The maximum pressure gradient method, involving use of a critical route, has been widely accepted and been traditionally used for the dimensioning of DH networks. In using this method, the maximum pressure gradient is taken as a limit, its being calculated on the basis of the maximum allowable pressure drop for the critical route in the network, using Eq. (8) [31].

$\nabla P_{\text {Max_Cr }}=\frac{\Delta \mathrm{P}_{\mathrm{Max}}}{\mathrm{L}\left(\mathrm{R}_{\mathrm{CR}}\right)}$

where $\nabla P_{M a x_{-}} C_{r}$ refers to the maximum pressure gradient, defined in terms of the critical route, where $L\left(R_{C R}\right)$ is the length of longest route for the Trekroner DH network, and $\Delta P_{\text {Max }}$ refers to the maximum allowable pressure drop of 8 bar, as dealt with in section 2.1.

Each pipe segment in the network was then dimensioned, using Eq. (9).

Maximize $D\left(P_{i-1, i}\right) \quad \forall i=1, \ldots, n_{i}$

Subject to the constraints

$\nabla P\left(P_{i-1, i}\right)=\frac{\Delta \mathrm{P}\left(P_{i-1, i}\right)}{\mathrm{L}\left(P_{i-1, i}\right)} \leq \nabla P_{\text {Max } \_ \text {Cr }}$ 
$D\left(P_{i-1, i}\right) \in T P$

where $\nabla P\left(P_{i-1, i}\right)$ refers to the pressure gradient, calculated according to pressure drop $\Delta P\left(P_{i-1, i}\right)$ of the pipe segment $P_{i-1, i}$

\section{Dimensioning Method 2. The Maximum Pressure Gradient, Multi-Route Method}

Dimensioning Method 1 leads to over-dimensioning of the pipe segments in the separate routes rather than the critical route of the DH network. If a pump can handle pressure loss in the critical route, it can also handle lesser pressure losses in other routes of the piping network when a closed loop system is involved [48,52]. In accordance with this, the maximum pressure gradient limit was determined for each route separately, using Eq. (10).

$\nabla P_{\text {Max } \_l}=\frac{\Delta \mathrm{P}_{\text {Max }}}{\mathrm{L}\left(\mathrm{R}_{\mathrm{l}}\right)} \quad \forall l=1, \ldots, n_{l}$

Then, the pipe segments were dimensioned within the limits of the maximum pressure gradient of the route to which they belonged, using Eq. (11). Since the main lines have several routes in common, the lower pressure gradient limits were determined from among the limits defined for the routes.

Maximize $D\left(P_{i-1, i}\right) \quad \forall i=1, \ldots, n_{i}$

Subject to the constraints:

$\nabla P\left(P_{i-1, i}\right) \leq \nabla P_{\text {Max_l }} \quad \forall l ; P_{i-1, i} \in P S_{l}$

$D\left(P_{i-1, i}\right) \in T P D$

\section{Dimensioning Method 3. The Optimization Method}

The pipe dimensions could not be reduced sufficiently by use of Dimensioning Method 2. The pressure gradient criteria, even applied in multi-routes separately, may have resulted in an over-dimensioned piping network. The remaining pressure potential may, because of the overly large dimensions that Dimensioning Method 2 provided, have had the possibility of allowing further reduction in pipe dimensions. An optimization algorithm was needed in order to utilize the potential of the maximum allowable pressure limit as much as possible in 
connection with each route of the DH network. Due to the complexity of DH network, the approach of searching for the minimum value of the objective function for each combination of available diameters in each pipe segment is not a particularly effective optimization method, even if it can provide an accurate global minimum [32]. The use of optimization algorithms saves time in the case of such large and complex DH networks, providing a solution which is close to the global minimum [31]. Continuously variable (though not commercially available) pipe diameters were found for the different pipe segments by use of an optimization method of this sort, the objective functions and the appropriate constraint functions being obtained using Eq. (12).

Minimise $\dot{Q}_{\text {Loss }}\left(D_{i}^{*}\right)$

Subject to the constraints:

$\Delta P\left(P S_{l}\right)=\Delta P_{\text {Max }} \quad \forall l=1, \ldots, n_{l}$

$D_{i}^{*} \in \mathbb{R}$

$D_{\min } \leq D_{i}^{*} \leq D_{\max }$

where $D^{*}$ is a continuous pipe dimension which is obtained and $D_{\min }$ and $D_{\max }$ are the corresponding minimum and maximum pipe diameters, respectively, of the pipe catalogue set TPD. The DH network contains $n_{l}$ leaf nodes.

Optimization was carried out by use of the optimization toolbox of the commercial software Matlab and of the "Active Set” algorithm there [53]. The continuous pipe diameters obtained were rounded upwards by means of Eq. (13) to pipe diameters that are commercially available.

$D\left(P_{i-1, i}\right)=\left\lceil D^{*}\left(P_{i-1, i}\right)\right\rceil ; D^{*}\left(P_{i-1, i}\right) \in \mathbb{R} \wedge D\left(P_{i-1, i}\right) \in T P D$

In order to ensure that the resultant optimal diameters were close to the global minimum in terms of heat loss from the DH network, the optimization was run from several different starting points [32,33,53,54]. 


\subsection{Evaluation of Pipe Dimensions}

The heat consumption profiles of the consumers involved can affect operation of the DH system considerably [11,33]. The optimal pipe dimensions were evaluated by means of the commercial software Termis, which in its basic assumption based on mass continuity in all the pipe segments that are linked with one another, i.e. the total heat demand of the consumers as a whole needs to be equal to the total heat supplied by the heat source. The DH piping network was also dimensioned in accordance with a simultaneity factor based on the peak heat load. Since this resulted in a mismatch between the heating demands of the consumers and the heat supplied by the heat source, there was the need in connection with the Termis simulations to adjust the heating demands of the consumers as a whole so that they correspond to the supplied heat in terms of the simultaneity factor. Several scenarios, representing -as a whole- the peak situation in the winter months, were created by means of randomly generated heat demand data based on use of the simultaneity factor, there two fields of application of this; the one being that of the junction of several pipe segments in the one by use of Eq. (14) and the same predecessor pipe segment by use of Eq. (15):

$S_{S S_{-} M P}=R N G \dot{Q}_{H L}^{*}\left(N_{i}\right) \quad \forall N_{i} \in \Gamma^{+}\left(N_{i-1}\right)$

Subject to the constraints:

$\dot{Q}_{H L}^{*}\left(N_{i-1}\right)=\dot{Q}_{H L}\left(N_{i-1}\right)$

$\dot{Q}_{H L}^{*}\left(N_{i}\right) \leq \dot{Q}_{H L}\left(N_{i}\right)$

where $\mathbf{S}_{\mathrm{SS} \_ \text {MP }}$ is the array of the heat demand values generated for the main pipe line, $R N G$ is a random number generator and $\dot{Q}_{H L}^{*}\left(N_{i}\right)$ is the heat load data generated at node $i$.

The second area of application of the scenarios referred to above is that of adjacent nodes in a given street pipe. Assume in Eq. (15) that follows that $N_{i}$ is the first node of the street line. 
$S_{S S_{-} S P}=R N G \dot{Q}_{H D}^{*}\left(N_{k}\right) \quad \forall N_{k} \in \Gamma^{+}\left(N_{i}\right) \wedge N_{k} \subset P S_{l} \quad \forall l=1, \ldots, n_{l}$

Subject to the constraints:

$\dot{Q}_{H L}^{*}\left(N_{i}\right)=\dot{Q}_{H L}\left(N_{i}\right)$

$\forall \dot{Q}_{H L}^{*}\left(N_{k}\right) \leq \dot{Q}_{H L}\left(N_{k}\right)$

where $\mathbf{S}_{\mathbf{S s} \_ \text {sp }}$ is the array of the heat demand values generated for the street line in question.

Let $n_{S S}$ be defined as the number of steady state scenarios generated. These steady state scenarios were ones created by the synchronized generation of sub-scenarios for the street and for the main lines by use of Eq. (16).

$S_{S S}=S_{S S_{-} S P} \cup S_{S S_{-} M P}$

where $\mathbf{S}_{\mathrm{Ss}}$ is the array of a scenario that contains the random heat demand data for the $\mathrm{DH}$ network as a whole.

The random number generator of MS Excel was used to define the seed for random number generation in terms of computer time so the steady-state scenarios were generated in different time configurations so as to avoid duplicate numbers [55]. The optimal pipe dimensions obtained were used as input data, the steady-state scenarios in the Termis model providing the heat demand input pertaining to the consumers in question. In the Termis model, the temperature of the heat supply from the root node and the return temperature from the consumers were set at $T_{S}=55{ }^{\circ} \mathrm{C}$ and $T_{R}=25{ }^{\circ} \mathrm{C}$, respectively. A pressure vessel having a holding pressure of 1.5 bara and a variable-speed pump, with performance being shown at Table 1, were located in the return line at the heat source [44]. In order to avoid a negative or an insufficient pressure difference across the different substations, the pressure difference was fixed at a minimum of $50 \mathrm{kPa}$ in each consumer's substation [27].

The Termis simulations allowed such parameters as the maximum static pressure in the DH network and the minimum pressure difference for the consumers to be checked in terms of the design limits. The confidence interval for the maximum static pressure was determined by 
means of the bootstrap method, which was used to resample the simulation results for the maximum static pressure reached in the DH network. The reliability of the confidence interval was increased by use of the bootstrap method [56].

\subsection{Network Types}

The energy performance of the DH network was also evaluated for networks of three different types and with substations of different types and booster pumps installed in the network.

Network Type 1. The DH network was connected to substations provided with $120 \mathrm{l}$ buffer tanks for DHW production (3 kW).

Network Type 2. The DH network was connected to substations having heat exchangers for DHW production (32.3 kW).

Network Type 3. Here the booster pumps were installed at the start of the pipe segments in each street in the case of $\mathrm{DH}$ networks of Type 2. The aim here was to have high maximum allowable pressure drop values as a design limit for short sequences of pipe segments, such as for sequences of pipe segments extending from the heat source to the booster pump and from the booster pump to the leaf node of a route in question. Eq. (12) was revised in accordance with the changed constraints, as shown in Eq. (17). The continuous pipe diameter values obtained were rounded up to the commercially available pipe diameters, by use of Eq. (13).

Minimise $\dot{Q}_{\text {Loss }}\left(D_{i}^{*}\right)$

Subject to the constraints:

$\Delta P\left(P S_{r_{-} j}\right)=\Delta P_{\text {Max }} \quad \forall N_{j} \in N M$

$\Delta P\left(P S_{i l \_l} l\right)=P_{S}\left(N_{i}\right)-P_{r}\left(N_{i}\right)+\Delta P_{B P} \quad \forall N_{i} \in S N$

$D_{i}^{*} \in \mathbb{R}$

$D_{\min } \leq D_{i}^{*} \leq D_{\max }$

where $P S_{r_{-} j}$ is the sequence of pipe segments from the heat source to the booster pump in the street that is longest of all, $\Delta P_{B P}$ is the additional head lift provided by the booster pump, $\operatorname{Ps}\left(N_{i}\right)$ and $P_{r}\left(N_{i}\right)$ are the values for the static pressure found at node $i, \mathbf{N M}$ is the set of the 
longest nodes contained in the main lines, and $\mathbf{S N}$ is the set of starting nodes for the different street lines.

\subsection{Network Layouts}

During the summer months no use is made of SH and the use of DHW is reduced, due to the absence of many consumers, who are on vacation. The stableness of the heat carrier medium due to reduction of the overall heat load results in a considerable drop in the temperature of the supply heat carrier medium [35]. A drop in temperature of the heat carrier medium at the supply point can be avoided by use of either of the following two network layouts:

Layout 1. Branched Network with a Bypass at Leaf Nodes: Equipping a substation with a bypass allows the cooled supply heat carrier medium to circulate through the return line back to the heat source, resulting in a higher return temperature and as a consequence in greater heat loss from the network and decreased efficiency in the extraction of heat from the heat source $[9,16,35]$. Installing thermostatic bypasses in substations in leaf nodes is widely accepted as a solution to this problem in traditional DH systems (Figure 1). When the temperature of the supply water drops below a certain temperature, the thermostatic bypass is activated to direct the supply water to the return line $[34,35]$. In Layout 1 , each of the leaf nodes of a branched DH network layout is equipped with a bypass set to a temperature of 50 ${ }^{\circ} \mathrm{C}$, and is provided with a dead band of $4{ }^{\circ} \mathrm{C}$ and a maximum flow limit of $0.056 \mathrm{~kg} / \mathrm{s}$.

Layout 2. Looped Network: Another method for preventing a temperature decline of the supply heat carrier medium is to provide the DH system with a looped network layout. Normally, a looped network is used in order to increase the security of supply [29]. In the present case, however, a looped network was employed so as to maintain circulation of the supply heat carrier medium by utilizing the dynamics of heat consumption, without the necessity of using a bypass, preventing in this way an increase both in the return temperature and in heat loss from the return line [57]. This is because the piping network in a looped 
layout supplies heat to a greater number of consumers in a given district than a branched layout does. This increases the stability of the supply temperature since, for example, when there is no heat demand in one particular location the heat carrier medium is circulated in the supply line to other consumers through the looped DH network [29]. Thus, the dimensions applying to a branched network were used in the looped network, in which external pipe segments are installed in the leaf nodes to form the looped layout (Figure 2). The diameters of these new external pipe segments were selected on the basis of the maximum diameter of the pipe segments (see Dimensioning Method 3) connected to leaf nodes.

\subsection{Dynamics of a DH Network}

The situation prevailing during the summer months was simulated in Termis for two network layouts with scenarios generated in accordance with there being different occupancy patterns of consumers then as a result of frequent vacation periods, and on the basis of a simultaneity factor effect on each pipe segment. First, the nodes of consumers present physically and found in the DH network were generated randomly by use of Eq. (18).

$C C_{\varphi_{-} S c}\left(N_{i}\right)=R N G C\left(N_{i}\right) \quad \forall i=1, \ldots, n_{i}$

Subject to the constraint:

$C C_{\varphi_{-} S c}\left(N_{i}\right) \leq C C\left(N_{i}\right)$

where $\mathrm{CC}_{\varphi_{\perp} \leq \mathrm{sc}}$ is the node list array that was generated, which includes the consumers currently present, together with subscripts representing the occupancy ratio $\varphi$, and the scenario number $S c$.

Dynamic heat demand scenarios $S_{\varphi \_s c}$ were then created by generating random heat demand data based on use of a simultaneity factor at each time step $t$, with two equations (14) and (15) applying to each of the predefined occupying-consumer nodes $\left(\mathrm{CC}_{\varphi_{-} S \mathrm{Sc}}\right)$. Later, each of the scenarios generated served as the basis for heat-demand input data for both of the DH network layouts, so as to maintain the same conditions throughout. 
Drops in temperature were also evaluated in terms of the DH network layout. The principle of "heating-degree day" measurement $[58,59]$ was used in assessing the level and the duration of the cooling down of the supply heat carrier medium at heat-demanding nodes during a given time interval. Supply temperatures predicted from time series simulations were evaluated in cases in which the supply temperature falled below a certain base temperature, by use of Eq (19).

$D M=\sum_{t=t_{o}}^{t_{f}} \sum_{i=1}^{n_{i}}\left(T_{S, t}\left(N_{i}\right)-T_{B}\right) \times \Delta t$

Subject to the constraint:

$C C_{\varphi_{S c}, t}\left(N_{i}\right) \neq 0$

where $D M$ is degree-minutes in ${ }^{\circ} \mathrm{C}$-min, $\Delta t$ is the time step value [minimum], $T_{S, t}\left(N_{i}\right)$ is the supply temperature during the time period $t$ at the node $N_{i}, T_{B}$ is the base temperature, and $t_{o}$ and $t_{f}$ refer to the initial and the final time step, respectively, of the time interval.

\section{$3 \quad$ Results and Discussion}

The pipe-node list for the Trekroner DH network model is shown in Table 2, together with the calculated heat load and mass flow needed in each pipe segment for different substation configurations.

\subsection{Dimensioning Methods}

Table 3 shows the resulting pipe diameters, the pressure drop values along the various routes and the heat loss from the DH network for each of three different dimensioning methods that was employed for Network Type 1. As can be seen in the table, for Dimensioning Method 1 the pressure drop values obtained failed to reach the maximum allowable design pressure for the critical route $R_{8}\left(\nabla P_{M a x_{-} C r}=1,617 \mathrm{~Pa} / \mathrm{m}\right)$. The same applies to Dimensioning Method 2, the $\nabla P_{M_{a} x_{-}} I$ values of which are given in Table 4 . The residual unused pressure drop potential 
resulted in both cases in the piping network being over-dimensioned. Dimensioning Method 3 yielded optimal dimensions that were smaller than those provided by the other two dimensioning methods. The pressure drop values obtained were close to the maximum allowable pressure drop, with a $14 \%$ reduction in heat loss there compared with Dimensioning Method 1. It was found that the optimization algorithm used in conjunction with Dimensioning Method 1 tended to give results representing an increase in the diameter of the pipe segments in the main line but a decrease in the diameter of the pipe segments of the street lines. Although the maximum velocity limit was not taken account of in the dimensioning stage, an optimal piping network resulted in a maximum flow velocity of 2.4 $\mathrm{m} / \mathrm{s}$ in the pipe segments labelled as 5, 10, 16, 23, 28 and 38.

\subsection{Evaluation of Pipe Dimensions with Respect to the Maximum Static Pressure}

Simulations using steady-state scenarios resulted in different maximum static pressures due to differences in heat consumption profiles within the DH network. The 95\% confidence interval for the maximum static pressure computed for the DH network was found to be $1010 \pm 3.112$ $\mathrm{kPa}$. Re-sampling then, obtaining values 50,000 times with use of the bootstrap method, resulted in $1007.5 \pm 0.015 \mathrm{kPa}$. In terms of this latter confidence interval, the maximum static pressure values obtained were considered to be satisfactory, despite their being slightly higher than the design limit for a static pressure of 10 bara. Peak winter conditions occur very seldom, and the safety factor employed in dimensioning the network equipment provides considerable leeway, virtually assuring that the network will not be damaged [60].

\subsection{Network Types}

Branched DH systems of three different network types were dimensioned by use of the optimization method associated with Dimensioning Method 3. The longest nodes of NM $\{13$ 
and 34$\}$ and the starting street-nodes of $\mathbf{S N}\{2,7,13,20,25$ and 31\} provided boundary conditions for the dimensioning method used for the DH network of network type 3. The three types of DH network differed in the degree to which the total length of each dimension of the pipes varied, as shown in Table 5. DH systems of network type 1 were found to clearly yield smaller dimensions, providing an $8 \%$ reduction in heat loss as compared with network type 2, due to a reduction in flow demand brought about by the buffer tanks in the substations. Use of network type 3 (which had booster pumps) resulted in a 2\% reduction in heat loss (for the $\mathrm{DH}$ network) as compared with network type 2 (which had no booster pumps). The design limit for the maximum allowable pressure difference for each street was increased after the installation of booster pumps, which provided a head lift of 3.8 bar (Table 6). For the streets belonging to the first and the fifth routes there was already a sufficient pressure difference ( 7.4 bar) between the supply and the return lines of the main line. Thus, no booster pump was installed in these routes, so as to avoid exceeding the static pressure of 10 bara for the streets in question, in accordance with the design. However the reduction in heat loss in Network Type 3 in comparison to Network Type 2 was not found to correlate with the level of reduction in diameter that comparison of the two revealed, due to the nonlinear characteristics of the heat loss transfer coefficient values obtained, e.g. $U(37.2)<U(26)$ and $U(20)<U(15)$ $[\mathrm{W} /(\mathrm{mK})]$.

\subsection{Network Layouts}

The Termis Model, with the optimal pipe dimensions provided with use of Dimensioning Method 3, was employed in connection with both of the network layouts with configuration of network type 1 (further information regarding this is provided in section 3.3). In each time series simulation, heat demand data served as the input data for assessing the heat demand of consumers. The time series were generated for a time range of $t_{f}-t_{o}=8$ hours, using a time step of $\Delta t=10 \mathrm{~min}$ for the scenarios, which were generated five times $\left(n_{T S}=5\right)$ for each 
presence ratio considered, those of $\varphi=75 \%, 50 \%$ and $25 \%$. Table 7 presents the frequency distribution of the heat demand in $\mathrm{kW}$ at the consumer nodes of the scenarios, as an illustration for occupancy ratios of $S_{25 \_3}, S_{50 \_2}$ and $S_{75 \_1}$. As can be seen in Table 7 , the heat demand at the consumer nodes increased as the occupancy ratio became higher. For an occupancy ratio of $25 \%$, some parts of the DH network contained only one or two occupying consumers, resulting in a low heat demand within the time range of the scenarios.

Table 8 shows the ratio of heat loss to the heat energy supplied within a time range of 8 hours, the return temperature being obtained at the heat source and the degree-minutes of the supply temperature within the DH network. The low heat demand density for $\varphi=25 \%$ was found to affect the operation of DH by producing large variation both in the ratio of heat loss to heat supply in Layout 2 and in the return temperature at the heat source in Layout 1 . Scenarios involving high occupancy ratios, such as $\varphi=50 \%$ and $\varphi=75 \%$, resulted in the values for both the ratio of heat loss to heat supply in Layout 1 and for the return temperature at the heat source in both layouts varying only slightly. The operating principles of the looped network did not allow the return heat carrier medium to circulate before the temperature had fallen to the return design temperature $\left(T_{R}=25^{\circ} \mathrm{C}\right)$. Thus, Layout 2 was found to maintain virtually the same return temperature, of about $T_{R}=25{ }^{\circ} \mathrm{C}$, at the heat source, regardless of the occupancy ratio and of the degree of variation in the heat demand. In contrast, considerable variation in the return temperatures at the heat source was encountered in Layout 1, due to the mixing of heat carrier mediums of supply and return with each other at return line. As can be seen in Figure 3, for each scenario the heat loss from the supply line was considerably greater for Layout 2 than for Layout 1, whereas in the return line a small change in heat loss occurred between the layouts, though only for an occupancy ratio of $25 \%$. The latter can be explained as being due to the low heat demand there and, as a consequence, the return temperature being raised by mixture of the return medium with the supply heat carrier medium. The positive 
correlation of degree-minutes and heat loss here suggests the heat loss to have occurred because of the long waiting time of the supply heat carrier medium at Layout 2. A high density of the heat demand reduces the waiting time of the supply heat carrier medium at Layout 2.

A detailed consideration of heat-demanding nodes with an unsatisfactory supply temperature can be rewarding. In scenario $S_{25 \_1}$, it is node 38 which is the most unsatisfactory heatdemanding node, in light of the fact that the supply temperature has a degree-minute value of $686{ }^{\circ} \mathrm{C}$-min. Figure 4 shows the changes obtained in the supply temperature at node $i=38$ during an 8-hour period and in the heat demands of the nodes $i=38$ and $i=37$, the only heatdemanding nodes in the local loop in this scenario. The heat demand patterns of the five consumers at the two nodes resulted in an inadequate supply temperature due to the supply heat carrier medium being overly stable for a long period of time.

In the same scenario $S_{25 \_1}$, the heat-demanding node $i=16$ developed a different dynamic behaviour, one that resulted in a degree-minute value of $419{ }^{\circ} \mathrm{C}$-min (Figure 5). In this local loop the number of heat-demanding consumers connected to nodes $i=16$ and $i=19$ was five, just as in the previous local loop example. However, the heat demand pattern at the heatdemanding nodes did not result in any extreme drop in the supply temperature, as it did at node $i=38$. The node $i=16$ was exposed to reductions in the supply temperature, slight in magnitude and of short duration, which is more or less acceptable from an engineering point of view.

Figure 6 shows changes over time in the supply temperature at the node $i=25$ in Layouts 1 and 2 in the scenario $\mathrm{S}_{25 \_4}$. In this part of the DH network the only heat-demanding nodes were $i=25$ and $i=21$, containing five consumers altogether. Although the same DHW heat-demand patterns were taken as input data for both layouts, the supply temperature profiles of the two layouts differed. The external pipe segment between nodes $i=23$ and $i=28$ was also the reason 
both for the excessive temperature drop in Layout 2 in addition to the reason of the low level of the heat demand of the nodes in question. At the same point in time, the heat consumption by the consumers was sufficient to maintain circulation within the supply line and produce an increase in the supply temperature.

\section{$4 \quad$ Summary and Conclusions}

The paper has presented a new method for designing low-energy district heating systems, pipe-dimensioning methods, network layout and types of substations being taken up in particular. It was shown that a considerable reduction in heat load in such systems can be achieved through taking account of simultaneity factor in planning of each pipe segment. An optimization method aimed at reducing heat loss in a DH network, also when pressure changes in the various routes through the system are at a maximum, was proposed, a method that can prevent the over-dimensioning of the piping network that readily occurs in the use of traditional dimensioning methods. Comparisons of different dimensioning methods showed that the "Maximum Pressure Gradient" method, when used in conjunction with the optimization method just referred to, was able to provide energy savings of some $14 \%$ in preventing heat loss from the DH network. Evaluation of the degree of optimality of a piping network by means of the commercial software Termis was carried out using heat demand scenarios that were randomly generated while at the same time taking account of the simultaneity factor that applied for each pipe segment separately. The results provided strong support for the validity of the optimization method referred to, and also for use of it ensuring that the system is able to withstand conditions of maximum static pressure with sufficient pressure differences obtained in each substation in the DH network. Analysis of different types of networks showed a DH network connected to substations having buffer tanks for DHW production (Network Type 1) to show an 8\% lower heat loss from the DH network than a DH network connected to substations having heat exchangers for DHW production 
(Network Type 2). A Type 3 network, in which booster pumps were installed in a Type 2 network, was found to make a considerable reduction in pipe dimensions possible as a consequence of increased maximum allowable pressure drop at the DH network. At the same time, only about a $2 \%$ saving through preventing heat loss by use of a Type 3 network rather than type 2 network was achieved. The fact that the saving here was so small appears to have been due to the nonlinear characteristics of the heat transfer coefficient. The studies reported on also deal with conditions of low heat demand during summer months when it can be important to prevent low supply temperatures in the DH network from developing. This can be achieved by of either of two different types of network layout, that of a branched DH network having bypass units (Layout 1) and of a looped DH network (Layout 2). Scenarios in which the heat demand patterns of consumers were based on use of simultaneity were generated, the input data thus obtained being analyzed by the Termis software in terms of differing occupancy ratios (25\%, 50\% and 75\%). Under low occupancy-ratio conditions (25\%, such ratios being common during the summers), a DH network can react sensitively to consumers' heat demand patterns, in the case of Layout 2 in terms of marked variations in heat loss and in the case of Layout 1 in terms of sudden variations in return temperature at heat source in response to different scenarios. One can note that the operational philosophy of Layout 2 is strongly oriented to the heat consumption of consumers. Low demand conditions can also result in the heat carrier medium remaining unused in the supply lines for extended periods of time, which can lead to excessive drops in temperature. In addition, external pipe segments located in looped networks can be a source of considerable heat loss. For occupancy ratios of $25 \%$ or less, there also tends to be a clear difference (up to $4{ }^{\circ} \mathrm{C}$ ) between the return temperature present at the heat source and the return temperature that was planned. Simulation results that were obtained pointed in a general way to Layout 1 being superior to 
Layout 2 in terms of the supply temperature in the DH network being delivered to consumers with as little loss of heat as possible.

A number of general conclusions not yet taken up can be drawn. One is that a district heating system should always be designed in accordance with what works best within the district itself. Another conclusion is that it is highly important to take into consideration, for each pipe segment separately, the degree of simultaneity of the heat consumers involved. In addition, it appears that significant savings can be achieved by use of the proposed optimization method, which makes use of the pumping head in all closed loops of a DH network. Buffer tanks for DHW production, installed in separate substations, were found to reduce the heat demand appreciably, enabling the pipe dimension of the $\mathrm{DH}$ network and the heat loss from it to be reduced as well. One can note too that the mixing of supply and return heat-carrier waters that can occur through bypasses being located in leaf nodes does not cause any excessive increase in temperature, except under conditions of extremely low heat demand, the return temperature there also tending to be rather moderate. One should note too that looped DH networks without a bypass tend to contain a considerable amount of supply heat carrier medium, which can lead under certain conditions to considerable drops in temperature and to greater loss of heat from the DH network than from a branched DH network having bypass units in the leaf nodes.

\section{References}

[1] Committee on Legal Affairs, European Parliament, Committee on Industry, Research and Energy. Energy performance of buildings (recast) ***I. 2010;C 184 E/263:3-5.

[2] Lund H, Möller B, Mathiesen BV, Dyrelund A. The role of district heating in future renewable energy systems. Energy 2010;35:1381-90.

[3] Lund H, Mathiesen BV. Energy system analysis of 100\% renewable energy systems-The case of Denmark in years 2030 and 2050. Energy 2009;34:524-31.

[4] Persson U, Werner S. Heat distribution and the future competitiveness of district heating. Applied Energy 2011;88:568-76. 
[5] Alberg Østergaard P, Mathiesen BV, Möller B, Lund H. A renewable energy scenario for Aalborg Municipality based on low-temperature geothermal heat, wind power and biomass. Energy 2010;35:4892-901.

[6] Østergaard PA, Lund H. A renewable energy system in Frederikshavn using lowtemperature geothermal energy for district heating. Applied Energy 2011;88:479-87.

[7] Çomaklı K, Yüksel B, Çomaklı Ö. Evaluation of energy and exergy losses in district heating network. Applied Thermal Engineering 2004;24:1009-17.

[8] Torío H, Schmidt D. Development of system concepts for improving the performance of a waste heat district heating network with exergy analysis. Energy and Buildings 2010;42:16019 .

[9] Olsen PK, Lambertsen H, Hummelshøj R, Bøhm B, Christiansen CH, Svendsen S et al. A new low-temperature district heating system for low-energy buildings. The 11th International Symposium on District Heating and Cooling 2008.

[10] Christiansen CH, Paulsen O, Bøhm B, Thorsen JE, Ting Larsen C, Jepsen BK et al. Development and demonstration of low-energy district heating for low-energy buildings. Main report and appendices [Udvikling og demonstration af lavenergi-fjernvarme til lavenergibyggeri. Hovedrapport og bilag] [In Danish]. 2009;EFP 2007:6-25.

[11] Benonysson A, Bøhm B, Ravn HF. Operational optimization in a district heating system. Energy Conversion and Management 1995;36:297-314.

[12] Foged M. Low temperature operation. DBDH 1999;1:3.

[13] Paulsen O, Fan J, Furbo S, Thorsen JE. Consumer Unit for Low Energy District Heating Net. The 11th International Symposium on District Heating and Cooling 2008:1-8.

[14] Hasan A, Kurnitski J, Jokiranta K. A combined low temperature water heating system consisting of radiators and floor heating. Energy and Buildings 2009;41:470-9.

[15] Mertoğlu O, Dokuz İ, Canlan A, Bakır N. Alternative energy sources and low temperature geothermal district heating [Alternatif enerji kaynakları ve düşük sicaklıklı jeotermal bölgesel 1sitma] [In Turkish]. TESKON 1999:917-29.

[16] Rämä M, Sipilä K. Challanges on low heat density district heating network design. The 12th International Symposium on District Heating and Cooling 2010:69-72.

[17] Lund H. Renewable energy systems: the choice and modeling of $100 \%$ renewable solutions. MA, USA: Elsevier Science \& Technology.

[18] Ren J, Zhu L, Wang Y, Wang C, Xiong W. Very low temperature radiant heating/cooling indoor end system for efficient use of renewable energies. Solar Energy 2010;84:1072-83.

[19] Ala-Juusela M, Rautakivi A. Summary report - Heating and cooling with focus on increased energy efficiency and improved comfort. VTT 2004;2256:11-54. 
[20] Schmidt D. New ways for energy systems in sustainable buildings - increased energy efficiency and indoor comfort through the utilisation of low exergy systems for the heating and cooling of buildings. Plea2004 2004;21.

[21] Wasilewski W. The influence of the consumer's installation parameters on district heating systems. Energy and Buildings 1988;12:173.

[22] 8 steps - control of heating system. : Danfoss.

[23] Dincer I, Hepbasli A. District energy systems. In: Anonymous Encyclopedia of Energy Engineering and Technology - 3 Volume Set (Print Version): CRC Press; 2007, p. 316-331.

[24] Rochas C. The case for district heating: 1000 cities can't be wrong! : DHCAN.

[25] Rosada J. Characteristics of district heating - advantages and disadvantages. Energy and Buildings 1988;12:163-71.

[26] Dobos L, Abonyi J. Controller tuning of district heating networks using experiment design techniques. Energy; In Press, Corrected Proof.

[27] Overgaard J, Knudsen S. District heating networks - choosing the right pipe dimensions. DBDH 2006;1.

[28] Yildirim N, Toksoy M, Gokcen G. Piping network design of geothermal district heating systems: Case study for a university campus. Energy 2010;35:3256-62.

[29] Sarbu I. Optimization of water distribution networks. Proceedings of the Romanian Academy Series A-Mathematics Physics Technical Sciences Information Science 2010;11:330-9.

[30] Winter W, Haslauer T, Obernberger I. Simultaneity surveys in district heating networks: Results and project experience [Untersuchungen zur Gleich-zeitigkeit in Nahwärmenetzen : Ergebnisse und Projekterfahrungen] [In German]. Euroheat\&Power 2001;30:42-7.

[31] González C, Macarulla B, Sallán D. Recursive design of pressurized branched irrigation networks. Journal of Irrigation and Drainage Engineering 2010:1-15.

[32] Bejan A, Tsatsaronis G, Moran M. Thermoeconomic optimization. In: Anonymous Thermal Design \& Optimization, New York: John Wiley \& Sons, Inc; 1996, p. 463-510.

[33] Mathews EH, Brenkman HF, Köhler PAJ. Optimization of pipe networks using standardized pipes. R\&D Journal 1994;10:45-51.

[34] Termis Help Manual. 2010;V 2.10.

[35] Li H, Dalla Rosa A, Svendsen S. Design of low temperature district heating network with supply water recirculation. The 12th International Symposium on District Heating and Cooling 2010:73-80. 
[36] Peng W, Pinghua Z. Research on network reliability of district heating systems based on the combined planar network model. The IEEE International Conference on Industrial Engineering and Engineering Management, IEEM 2009 2009:233-6.

[37] Thorsen JE, Christiansen CH, Brand M, Olesen PK, Larsen CT. Experiences on lowtemperature district heating in Lystrup - Denmark. International Conference on District Energy, in press.

[38] Brand M, Thorsen JE, Svendsen S, Christiansen CH. A Direct Heat Exchanger Unit used for Domestic Hot Water supply in a single-family house supplied by Low Energy District Heating. The 12th International Symposium on District Heating and Cooling 2010:60-8.

[39] Brand M, Dalla Rosa A, Svendsen S. Performance of Low Temperature District Heating Systems for Low Energy Houses. IEA ECBCS ANNEX 49 2010:174-83.

[40] Danish Building Regulation 2010. 2011;2010.

[41] Zinko H, Bøhm B, Sipilä K, Kristjansson H, Ottosson U, Rämä M. District heating distribution in areas with low heat demand density. DHC2008 2008;11.

[42] The bonded pipe - Logstor product catalog. 2009;2011:10.

[43] The twinpipes - Logstor product catalog. 2009;2011:58.

[44] Steer KCB, Wirth A, Halgamuge SK. Control period selection for improved operating performance in district heating networks. Energy and Buildings 2011;43:605-13.

[45] Dalla Rosa A, Li H, Svendsen S. Method for optimal design of pipes for low-energy district heating, with focus on heat losses. Energy 2011; In Press, Corrected Proof:1-9.

[46] Gabrielaitiene I, Bøhm B, Sunden B. Modelling temperature dynamics of a district heating system in Naestved, Denmark - A case study

[47] Vestergaard JB. The distribution network (August). Lecture note presented at Summer School District Energy, Århus, Denmark. 2010.

[48] Sanks RL. Pumping station design. : Elsevier Gulf, 1998.

[49] Clamond D. Efficient resolution of the colebrook equation. Industrial \& Engineering Chemistry Research 2009;48:3665-71.

[50] Dalla Rosa A, Li H, Svendsen S. Steady state heat losses in pre-insulated pipes for lowenergy district heating. DHC12 2010:83.

[51] Wallentén P. Steady-state heat loss from insulated pipes. 1991;TVBH-3017:25-7.

[52] Messina JP. Branch-Line pumping systems. In: Karassik IJ, Messina JP, Cooper P, Heald CC, editors. Pump Handbook, USA: McGraw-Hill; 2001, p. 83-90.

[53] Matlab Help Manual - Optimization Toolbox. 2010;R2010b. 
[54] Leyffer S, Mahajan A. Nonlinear constrained optimization: methods and software. 2010;ANL/MCS-P1729-0310:1-12.

[55] Generating a Random Number without RAND() in Excel ;2011.

[56] Efron B, Tibshirani R. Bootstrap methods for sandard errors, confidence intervals, and other measures of statistical accuracy. Statistical Science 1986;1:pp. 54-75.

[57] Langendries R. Low return temperature (LRT) in district heating. Energy and Buildings 1988;12:191-200.

[58] Degree Days. In: Anonymous Energy: Management, Supply and Conservation (Second Edition), Oxford: Butterworth-Heinemann; 2009, p. 343-346.

[59] Durmayaz A. An application of the degree-hours method to estimate the residential heating energy requirement and fuel consumption in Istanbul. Energy 2000;25:1245.

[60] Worm J, Jørgensen H, Thorsen JE, Bennetsen J, Larsen CT, Juhl O et al. Demonstration of low energy district heating system for low energy building in ringgårdens Afd. 34 in Lystrup [Demonstration af lavenergifjernvarme til lavenergibyggeri i boligforeningen ringgårdens afd. 34 i Lystrup] [in Danish]. 2011; in press. 


\section{List of Tables}

Table 1. Pump data used in the Termis Model.

Table 2. List of the pipes and the nodes in the Trekroner DH network.

Table 3. Pipe diameters, pressure drop values in the different routes, and heat loss from the DH network, as obtained for each of three different dimensioning methods.

Table 4. Maximum pressure gradient limits $\nabla \mathrm{P}_{\text {Max }}$ for each of the routes, and the maximum pressure gradient values obtained.

Table 5. Pipe diameters and heat loss from the DH network, as obtained for each of three different DH network types.

Table 6. Pressure changes after installation of a booster pump in the first pipe segment in every street.

Table 7. Frequency distribution of the heat demand in different nodes during a time series, for each of three different scenarios that were generated, $S_{75 \_1}, S_{50 \_2}$ and $S 25 \_3$.

Table 8. Ratio of heat loss to heat supply in the DH network, together with the return temperature at the heat source and the degree-minute values obtained, for each of two network layouts. 


\section{List of Figures}

Figure 1. Diagram of a branched DH network for Trekroner.

Figure 2. Diagram of a looped DH network for Trekroner.

Figure 3. Overall heat loss from the DH network over a time series, as obtained for (a) supply line and (b) return line.

Figure 4. Changes over time in the supply temperature and the DHW heat demand (S25_1, $\mathrm{i}=38)$.

Figure 5. Changes over time in the supply temperature and the DHW heat demand (S25_1, $\mathrm{i}=16)$.

Figure 6. Changes over time in the supply temperature and the DHW heat demand for each of the two different layouts (S25_4, i=25). 